\title{
Near-field measurements using directive antennas
}

\author{
Hansen, Jesper; Jensen, $F$
}

Published in:

Antennas and Propagation Society International Symposium

Publication date:

1970

Document Version

Publisher's PDF, also known as Version of record

Link back to DTU Orbit

Citation (APA):

Hansen, J., \& Jensen, F. (1970). Near-field measurements using directive antennas. In Antennas and Propagation Society International Symposium (Vol. Volume 8, pp. 284-287). IEEE.

\section{General rights}

Copyright and moral rights for the publications made accessible in the public portal are retained by the authors and/or other copyright owners and it is a condition of accessing publications that users recognise and abide by the legal requirements associated with these rights.

- Users may download and print one copy of any publication from the public portal for the purpose of private study or research.

- You may not further distribute the material or use it for any profit-making activity or commercial gain

- You may freely distribute the URL identifying the publication in the public portal

If you believe that this document breaches copyright please contact us providing details, and we will remove access to the work immediately and investigate your claim 
VII.2 - 9:00 A.M., Wednesday, 131 Hitchcock Hall

NEAR-FIELD MEASUREMGATS USING DIRECTIVE ANTRRNAS

J. E. Hansen and F. Jensen

Laboratory of Electromagnetic Theory

The Technical University of Denmark

Lyngby, Denmerk.

The problem of determining the far field of an antenne by computation when the near-field pattern is the measured quantity has stimulated several investigations in recent years ${ }^{1-8}$. The importance of the problem rests mainly on the fact that the minimum distance required for a far-field measurement often turns out to exceed the length of the measurement range available.

In principle, the far-field pattern of an antenna can be determined to a given accuracy at any measurement distance by direct measurement, provided the antenna with which the measurement is made is sufficiently directive. A compressed measurement range which utilizes this technique hes been described recently by Johnson 6 .

Application of a moderetely directive near-field probe in connection with subsequent computation for determining the farfield pattern has been reported by Brown and Jull2. The theory in 2 applies to two-dimensional antennas and makes use of cylindrical mode expansions of the radiated field.

A three-dimensional method using a spherical mode representation for the unknown field has been considered by James and Longdon ${ }^{3}$. This method uses omnidirectional probes (short dipoles and loops) in order to measure the near field directly, and is based on the knowledge of the radial components of the electric and magnetic near field. Near-field far-field transformations using spherical wave expansions in connection with measurement of tangential electric fields have been investigated by Ludwig.

In this paper, a far-field prediction method is presented in which a measuring entenna of arbitrary directivity ( $B$ in fig. 2) is assumed. This is specified through the (known) expansion of its field into spherical vector-wave functions centered at $0^{\prime}$. The unknown anteane $A$ (not shown) is centered at $O$ and described in terms of spherical modes with the unknown coefficients $\mathrm{e}^{\operatorname{mnn}}$ and $b^{\min }$. city theorem

The theoretical derivation is based on the Lorentz recipro-

(1) $\int_{S}\left(\overline{\mathrm{E}}_{\mathrm{A}} \times \overline{\mathrm{H}}_{\mathrm{B}}-\overline{\mathrm{F}}_{\mathrm{B}} \times \overline{\mathrm{H}}_{\mathrm{A}}\right) \cdot \mathrm{d} \overline{\mathrm{E}}=0$

Here, $\left(\overline{\mathrm{I}}_{\mathrm{A}}, \overline{\mathrm{H}}_{\mathrm{A}}\right)$ is the field which exists when antenne $A$ is used as 
a transmitting antenne and $B$ is receiving. This field consists of the following three parts: 1) The field incidert on $B .2$ ) The field transmitted in the waveguide behind B. 3) The field reflected from $B$. Similarly, $\left(\bar{s}_{B}, \bar{H}_{B}\right)$ is the field which exists when $B$ is trarsmitting and $A$ is receiving.

The surface of integration $S$ in (I) is composed of the two spinerical surfaces $S_{1}$ and $S_{2}$ and a reference plane $S_{3}$ in the waveguide of $\mathrm{B}$. The trree surfaces are assumed to be interconnected in a manner suitable to enclose the solrce-rree region between $A$ and $\mathrm{B}$.

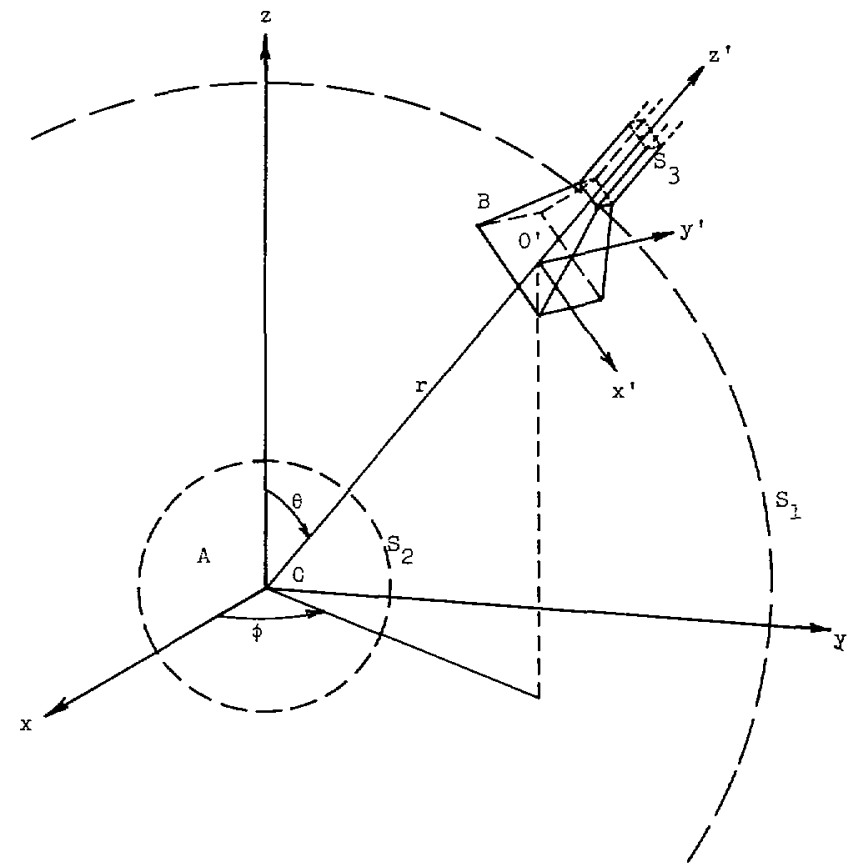

Fig. 1. Positiors of antenras $A$ and $B$ and surfaces of integration $\mathrm{S}_{1}, \mathrm{~S}_{2}, \mathrm{~S}_{3}$. 
The contribution to (1) from the waveguide reference plane $\mathrm{S}_{3}$ yields the signal $\mathrm{W}(\mathrm{r}, 6, \phi)$ received by $\mathrm{B}$ when $\mathrm{A}$ transmits. the contribution from $S_{1}$ tends to zero as the radius of $S_{1}$ is expanded towards infinity. Calculation of the contribution from $S_{2}$ is the crucial step and involves application of the rather complicated translation and rotation theorems for the spherical vector wave functions 9,10 .

The final result upon insertion in (1) is an equation of the following form

$$
\sum_{m, n}\left[a^{m n} f_{m n}(r, \theta, \phi)+b^{m n} g_{m n}(r, \theta, \phi)\right]=W(r, \theta, \phi)
$$

where $-n \leq m \leq n, l \leq n<\infty$. The functions $f$ and $g$ are involved functions details of which will be given in the paper. In the simple case where $B$ is an $x^{\prime}$-oriented short dipole eq. (2) simplifies to

$$
\sum_{m, n}\left[a^{m n}\left(\bar{M}_{m n}(r, \theta, \phi)\right)_{\theta}+b^{m n}\left(\overline{\mathbb{N}}_{m n}(r, \theta, \phi)\right)_{\theta}\right]=W(r, \theta, \phi)
$$

where $\bar{M}$ and $\bar{N}$ are the ordinary spherical vector wave functions. The left-hand side of eq. (3) is simply the $\theta$-component at $(r, \theta, \phi)$ of the electric near field fram $A$.

Equation (2) forms the main result of the paper. It is assumed that the left-hand side may be truncated to a finite number of terms, $k$. Thus, if $W$ is measured at $k$ different positions $(r, \theta, \phi)$, a system of $k$ linear equations in the $k$ unknown coefficients $a^{m n}$ and $b^{m n}$ is formed. Upon solution of this system the field from $A$ is known everywhere.

\section{REFERENCES :}

1. J. Brown, "A theoretical analysis of some errors in aerial measurements", Proceedings IEE, Monograph No. $285 \mathrm{R}$, vol. 105C, pp. 343-351, (February 1958).

2. J. Brown ana E. V. Jull, "The prediction of aerial radiation patterns from near-field measurements", Proceedings IEE, vol. 108B, pp. 635-644, (November 1961).

3. J. R. James and I. W. Longdon, "Prediction of arbitrary electromagnetic fields from measured data", Alta Frequenza, vol. 38, pp. 286-290, (Hay 1969).

4. M. A. K. Hamia, "The radiation pattern of an antenna from near field correlation measurements", IEEE Trans. Antennas and Propagation, vol. AP-16, No. 3, pp. 351-353, (May 1968). 
5. R. Mittra and $\mathrm{n}$. A. Imoriale, "Gain and pattern measurements of large aperture antennas in the Fresnel zone", IFEF international antennes and propagation symposium, Univ. of Texas, Austin, 1969, I6, p. 40.

6. R. C. Johnson, H. A. Ecker, and R. A. Moore, "Compact range techniques and reasurements", IFEE Trans. Antenras and Propagation, vol. AP-17, Ho. 5, pp. 568-5?6, (September 1969).

7. F. Jensen, "The influence of inaccuracies of measurements on near-field - far-field correlation", Proceedings of the Fourth Colioquium on Microwave Commication, Budapest 1970 , vol. 3, ET-13.

8. A. C. Ludwie, private communication.

9. S. Stein, "Addition theorems for spherical wave functions", Quart. Appl. Metr., vol. 19, Ho. 1, pD. 15-24, (1961).

10. 0. R. Cruzan, "Translational eddition theorems for sphericel vector wave functions", Quart. Appl. Math., vol. 20, No. 1, pp. 33-40, (1962). 